\author{
Alexandra E. Krawiec ${ }^{1}$ \\ Polish Connector for RSA, Royal Society for the Encouragement \\ of Arts, Manufactures and Commerce, Great Britain
}

\title{
Socio-Economic Implications of Female Inclusion in Organizational Structures and in Leadership Positions
}

\begin{abstract}
The perception of women's statutory place within organizations has been influenced by gender bias, which has led to discrimination. Lowering barriers related to gender inequality and introducing constructive changes takes a surprisingly long time. This procrastination can, to some extent, be attributed to the fear of potential economic costs, which is a misconception. A deeper understanding of the interplay between socio-economic factors and gender inequality within organizations can result in designing better, less biased, more merit-based structures and provide women with better career opportunities. Countries and organizations promoting gender equality practices prove that women's inclusion in the labor market can be 'cost-effective' and beneficial in socio-economic terms.

This article analyzes selected determinants of female underrepresentation in organizations, and in leadership positions in particular. The author points out to the rich body of research and to the multiple implications of gender inequality. Among the change resistant, deeply rooted factors, those originating in culture have a significant impact on women's inclusion in organizations. This paper focuses on macro problems, and explains why some determinants are more persistent than others, and still influence gender equality at all levels of organizational structures. The determinants are systematized, analyzed using statistical data, and rooted in a wide body of research. The article also presents potential future developments and available tools that can be employed to speed up changes leading to gender equality in organizational structures, particularly in leadership positions.
\end{abstract}


Keywords: gender gap, women's leadership, organizations, gender inequality, socio-economic impact

JEL: E.24, J13, J16, J24, J70, M12, M14, O11

\section{Introduction}

"Business and human endeavors are systems (...). We tend to focus on snapshots of isolated parts of the system. And wonder why our deepest problems never get solved."

Peter Senge, The Fifth Discipline:

The Art and Practice of The Learning Organization [1990]

Women's exclusion from organizational structures, especially from their highest strata, has strong cultural roots. For the last thirty years, various transformations have finally allowed women to enter organizational structures, and included them in top management. Through gradually emerging opportunities, women have finally been given a chance to put their skills to practice, and work their ways into male-dominated C-Suits. This advantageous, but still rare and relatively new situation in the labor market, triggered ongoing transformations. These in turn introduced new challenges, which require women, especially those in leadership positions, to be vigilant, learn new skills and constantly upgrade their knowledge to function in highly competitive environments [Ely et al., 2011; Gratton, Erickson, 2007; Eagly, Carli, 2007; Smith, Bettio, 2008]. Faced with the need to adapt to their altering statutory situation, women have been developing new roles and different identities. The latter appeared to be a complex process, involving predominately male environments, male role models and mostly male partners.

In this article we refer to the notion of leadership in the managerial, rather than the charismatic, sense. In taxonomic terms leadership hereto is similar to holding top managerial positions. Thus, leadership is defined as a skill requiring all the necessary competencies to perform highly demanding managerial functions pertaining to the broad spectrum of knowledge in HR, finances and legal matters.

Cultural heritage reveals some of the causes behind women's discrimination. In the past, the managerial structures of organizations were, with very few exceptions, almost entirely male [Eagly, Johannesen-Schmidt, 2001]. Until the XXth century in most parts of the world male bosses or men-only boards of directors found it difficult to allow female into their ranks as their equals and partners, rather than subordinates like secretaries or assistants. This historical legacy inevitably led to a broad spectrum of long-lasting negative determinants that continue to hinder women from attaining leadership positions. In the last decades women have measured up, or outperformed their male counterparts in many spheres of life, meeting requirements that were often created for men only. However, they still face barriers and are the targets of bias-driven negative evaluation. 
This study is intended to provide an extensive account of the current state of affairs concerning women's roles and positions in organizational structures of different types, and facilitate a better understanding of the determinants and dependencies that govern their position. We begin by characterizing the overall state of gender inequality, relying, where possible, on statistical data. In the subsequent section, we focus on the economic consequences of women's inclusion in governments, global organizations and companies. The third part provides a comprehensive list of key determinants responsible for the current situation. That section offers a taxonomy of determinants in the managerial context, and links them to culture and psychology. In the two following sections, we discuss their complexities in an attempt to identify the crucial causes and manifestations of gender inequality. In the conclusion we focus on positive consequences of including women in top managerial positions and propose policies to address the identified problems.

\section{State of the Art}

Before turning to the scientific evidence on gender inequality, we begin with a description of a more casual event recently discussed in the popular media; that is, the case of Stella Creasy, a member of Parliament in the UK, who campaigned for a women to be placed on the pound sterling banknote. This campaign opened up a Pandora's box of misogynistic reactions against Creasy, who received multiple hateful and threatening messages through social media. This discriminatory feedback happened in Great Britain - one of the most socially and economically developed European countries. This case could be analyzed from different perspectives, but each points to the depth of a problem, potentially detrimental consequences, and the need for building public awareness about the negative impact of inequality on a country's socio-economic conditions [Bowcott, 2014].

For the last ten years, the problems related to women's place in organizational structures have been analyzed in the scientific literature and widely discussed at numerous conferences organized by, among others, the World Economic Forum (WEF), United Nations (UN), the European Commission (EC) and leading universities. There is a broad consensus that insufficient support and change-resistant culture factors preserve traditional views of women's social roles and, ipso facto, thwart women's access to leadership positions [Chickering, 1969]. These facts are supported by numbers. In 2015 women accounted for $17 \%$ of World Economic Forum members, $11 \%$ of positions in C-Suits of top High Performance Companies (HPC), $8 \%$ of heads of governments, $6 \%$ of heads of states, and a staggeringly low 3.4\% of the CEOs listed in Fortune Global 500 [Fortune, 2015].

According to the Gender Equality Index Report of the European Institute of Gender Equality [Humbert et al., 2015], in $201238.8 \%$ of women in EU countries were employed full time, compared to $55.7 \%$ of men (participation rates in employment in full-time equivalence), yielding a gender gap on this indicator of $16.9 \%$. Poland is close to the EU's 
averages, with this indicator valued at $41.4 \%$ and $58.1 \%$ for women and men respectively, and a gender gap of $16.7 \%$. Sweden, arguably the most progressive country is in this respect, exhibits a $9.2 \%$ gap (55.3\% for women, $64.5 \%$ for men).

When analyzing 2013 global employment risks data, International Labour Organization reported a female employment-to-population ratio of $47.1 \%$ [ILO, 2015] and that women often "bear disproportionate responsibilities for unpaid care work," which is an important economic factor reflecting the level of female job market exploitation. These data are reflected in differences in the duration of working life, which according to Humbert et al. [2015] is 5.4 years lower for women (32.2 years) than for men ( 37.6 years) in the EU. In Poland, these figures are 29.5 and 34.6 years, respectively, resulting in a slightly smaller gender gap of 5.1 years. In Sweden, that gap is only 2.5 years ( 39.3 and 41.8 years respectively).

When considering gender-related economic indicators, Humbert et al. [2014] rely on purchasing power standards (PPS), defined as an 'artificial currency' keyed to capture the cost of 'the same amount of goods and services in each country' [Eurostat, 2014]. The PPS of earnings for women in EU amounts to 2018 for women and 2528 for men (gender gap of 510, i.e., almost 25\%). For Poland, a less affluent Central and Easter European (CEE) country, these numbers are 1228 and 1459, respectively (gap of 231, i.e., 19\%). For Sweden - a leader among EU countries - the analogous figures are 2281 vs. 2737 (gap of 456, 20\%).

From the global perspective presented in the ILO report [2015], in most countries women are paid on average $25-40 \%$ less than men while contributing to unofficial (and difficult to estimate) unpaid household- and care giving-related chores. In 2013, it was reported that almost $50 \%$ of the global population works in low-valued jobs under conditions unprotected by law [ILO, 2015].

The problem of gender inequality extends beyond the statistical data; it is rooted in culture, social norms, and women's self-esteem, which often determine the career choices of young people entering the job market. During the 2015 UN Women UK and Government Equalities Office Conference, Nicky Morgan, the Secretary of State for Education and Minister for Women and Equalities, noted that in the UK, one of the best educated UE-28 countries:

"Even now, female graduates often choose subjects that lead into the lowest paid sectors. In fact, 22\% of the gender pay gap can be explained by the industries and occupations women work in" [Morgan, 2015].

This is consistent with the thesis that cultural, social, and psychological determinants can play a greater role than more tangible factors. The female graduates mentioned above may not aspire to better-paid jobs because they assume that they either do not deserve them (low self-esteem), have marginal chances to get them, or, once they get them, will face unfavorable working conditions in a predominantly male environment.

On the positive side, the situation is more favorable for women when it comes to education. According to the Eurostat report cited earlier [2014], women in the EU are more likely than men to attain higher education: $24.1 \%$ of women graduate from tertiary 
education institutions vs. $22.8 \%$ of men. In Poland, the percentage of women that graduate from tertiary education (23.8\%) is very close to Europe's median, but the analogous figure for men is much lower (17.3\%), so the difference is strongly in favor of the former (by 6 percent points). In Sweden, the difference is even more prominent, amounting to $33.9 \%-24.6 \%=9.3$ percent points. The only EU countries with more college educated men than women are Austria, Germany, Luxembourg, and the Netherlands.

Unfortunately, the education of women has not translated into their participation in top management. Overall in the EU, women account for only $16 \%$ of board members of the largest national companies and in Poland, they fare slightly worse, with only $12 \%$ of women occupying such posts. The proportions in Sweden are better (26\% women vs. $74 \%$ men), but even Finland, which scores best in this respect, is still far from a 50:50 ratio with only $29 \%$ women vs. $71 \%$ men in such posts.

In the macro-economic context, women's situation in the labor market is strongly correlated with each country's GDP. Though in all economies culture plays an important role in creating or reinforcing determinants, there is a clear demarcation line between women's economic involvement in developed and developing economies. In developing countries where basic human needs are not being met, it is difficult to provide sufficient opportunities and encourage women to become leaders. Women who struggle with poverty, face insufficient medical care, and limited access to contraceptives and education, often become mothers at a very early age and lag far behind men on statutory ladders.

In the developed countries, even though the number of highly qualified prospective female leaders is much higher, the problem of low number of female leaders still exists but the causes are different. Reduced access or unaffordable child-care, long working hours, lower wages relative to men, and other gender-related challenges can weaken women's ambitions and discourage them from reaching for top positions. The insufficient support and fear of potential cost of full involvement in professional activity are amongst the main causes of women's low participation in the labor market and leadership positions.

It may be worth mentioning that those few women who are already leaders bear the additional responsibility of becoming potential role models for prospective female leaders. Researchers agree that women in both developed and developing countries are in need of more versatile support from both gender groups [Ely 1994; Komives et al. 2005; Ibarra 1990, Ibarra et al. 2014; Eagly, Carli, 2007; Smith, Bettio, 2008].

\section{The Impact of Female Economic Inclusion and Female Leadership on Organizations}

Existing research has identified at least three major areas in which global economies can benefit from women's increased involvement in labor markets: 
- overall faster economic growth [UNW 2015; OECD, 2012],

- families benefiting from women's financial contribution or control over family budgets [The World Bank, 2012],

- decrease in child mortality, due to women's better education and their engagement in the labour market [World Bank Gender Data Portal, 2015].

The positive consequences of women's inclusion in the labor market are clear. Regarding the more specific aspect of women in higher ranks of organizations, the Catalyst Report of March 2011 [Carter et al., 2011] indicates that women leaders provide highly beneficial input to the companies they lead. In the report, the Catalyst group, a think-tank and NGO created to study social and economic challenges, summarized the relationship between the share of Woman Board Directors (WBD) and several economic performance indicators for the Fortune 500 companies. From 524 companies that appeared in the Fortune 500 index during 2005-2009 period, the top quartile included companies with 19 or more percent of WBDs, and in the bottom quartile exhibited up to 9 percent of WBDs. Companies in the top quartile observed 16 percent greater return of sales (ROS) ( $t$-test $p<0.1$ ), and 26 percent greater return on invested capital (ROIC) than the companies in the bottom quartile; no statistically significant difference in return on equity (ROE) was observed between these groups.

Using the same data, we also investigated the impact of a high continuous commitment to gender diversity. From the above 524 companies, 48 companies that had at least three WBDs in four out of five years in 2005-2009 were selected. The control group included the 24 companies with the lowest numbers of WBDs on board (no WBDs in most cases). The companies with a high commitment to gender diversity almost doubled their ROS compared to the control group (84 percent increase), and experienced a 60 percent increase of ROIC and 46 percent increase of ROE in the relevant time period. All of these differences were statistically significant according to $t$-test $(\mathrm{p}<0.1)$. See [Carter et al., 2011] for other details.

According to literature, gender inequality has a number of tangible consequences for a country's economic and social welfare, which are closely interrelated, and there are five important ways in which women can contribute to the economic development that have been analyzed for Europe [Smith and Bettio, 2008] but yield results that are universally valid. The main directions selected by Smith and Bettio include:

- quantitative improvement in female labor market participation,

- qualitative improvements through effective use of investments in human capital,

- women's contribution to growth through economic independence and their participation in the consumers market,

- integration of women into the fiscal system,

- women's role in childbearing.

These findings are consistent with other data inputs; for example, the McKinsey report [McKinsey, 2007] takes into account four main areas measuring organizational 
excellence: transformational change (i.e., leadership, culture), organizational design, merger management, and human capital and concludes that organizations with at least three females in top management positions scores higher than those without female managers. In Europe, examples from Sweden indicate that companies with top female managers have higher profits than those with male exclusive boards [Catalyst 2004; Datta Gupta et al., 2008]. Despite these findings, women still face inequality, fewer career advancement opportunities, and lower wages. In other words, women's work is often undervalued [Schwab, 1986].

The above discussion on women as key managers indicates that a pronounced presence of female leaders on the boards of directors of large enterprises is beneficial to their performance. Sustained commitment to gender diversity would presumably be particularly fruitful in management, and there is no apparent reason why the same should not hold true for all types and sizes of companies. A caveat regarding these observations is that the underlying data and statistical methodology employed does not prove causality between the considered variables (fraction of WBDs and economic indicators), as per the well-known adage that correlation does not imply causation. Therefore, this analysis is conditioned on both the impact of WBD percentages on a company's welfare as well as a potential reverse phenomenon, i.e., that well-performing large enterprises may attract high numbers of women willing to become board directors. Nevertheless, one may safely assume that after adjusting these results accordingly (given data availability), the overall conclusion of beneficial impact of female presence in governing bodies would still hold.

Another report on living standards, the Inclusive Growth Report published by World Economic Forum (WEF), provides analyzes data on living standards regarding 112 of the world's economies [Samans et al., 2015]. Ten indicators for the last eight to ten years are applied to countries grouped depending on economic development:

- advanced economies (GDP per capita $>\$ 17,000,30$ countries),

- upper-middle income (GDP per capita in range $\$ 6,000$ to $\$ 17,000,26$ countries),

- lower-middle income (GDP per capita in range \$1,320 to \$6,000, 37 countries),

- low income (GDP per capita below \$1,320, 16 countries).

The indicators discussed in the report involve three indices related to gender equity: education, pay, and health. We focus here on the former two, as they directly impact women's presence and role in organizations and their leadership capabilities.

The WEF Global Gender Gap in Education (GGE) index is based on the ratio of female to male literacy and net enrollments in primary, secondary, and tertiary education using data from the Education Database maintained by UNESCO's Institute for Statistics.. When GGE is equal to 1 overall literacy and enrollments are the same for both genders; values of less than 1 indicate underrepresentation of women in these areas.

In all economic groups delineated above, there are countries with the 'ideal' GGE of 1. This score was achieved in 19 out of 30 advanced economies (including the US, Sweden, Australia and Slovenia). GGE is overall relatively high in this group, with the lowest value 
of 0.88 attained by South Korea, 0.93 by Italy, 0.96 by Japan, and 0.97 by Czech Republic. All remaining countries in this group have a GGE of 0.99 or more.

In the upper-middle income group, Turkey attained the lowest GGE of 0.8 , nine of 26 countries have a GGE of 1 , and in 20 countries the GGE is at least 0.99 .

In the lower-middle income group, the GGE is the lowest for Pakistan (0.65), followed by Jordan and Iran (0.71), Yemen (0.72), Algeria (0.73), Morocco (0.77), India (0.78), Egypt (0.82), Tunisia and Mauritania (0.83). Ten countries in this group have a GGE < 0.9 , nine have a GGE of 1 , and for 21 countries the GGE is 0.99 .

In the low income group, the lowest GGE values are for Bangladesh (0.85), Nepal (0.89) and Mali (0.91). However, all the remaining 13 countries have a moderately high GGE of at least 0.97 , and over half (9 out of 16) have a GGE of 1.

The WEF Gender Pay Gap (GPG) index is the ratio of female-to-male wages in various sectors and/or the gross national income purchasing power parity (PPP) terms as of 2011, calculated based on data provided by the World Bank and United Nations Development Program. Similarly to the GGE, the 'ideal' value of this index is 1. See [Samans et al., 2015] for more details.

There is only one country in the world with a GPG $\geq 1$; Denmark, where the GPG is actually greater than one (1.03). Denmark, which belongs to the group of advanced economies, is followed in that group by Australia $(\mathrm{GPG}=0.96)$ and Sweden (0.94). Strikingly, the next country, Germany, has much lower GPG of 0.84 . Out of the 30 countries in this group, 24 have a GPG of 0.8 or less, i.e., with women earning on average at most $80 \%$ of men's earnings in comparable positions. Nine countries in this group have a GPG "0.6, i.e., in which women earning (at most) $60 \%$ of men's salaries, on average. At the bottom of the ranking is South Korea, with a GPG of 0.48.

In the upper-middle group, the best GPG is only 0.71 , which exists in Croatia and Romania. The median GPG in this group is 0.61 , and in four of the 26 upper-middle group countries (Turkey, Azerbaijan, Mexico and Chile) women earn on average half of men's wages, i.e., have a GPG of 0.5 or less.

In the lower-middle income group, the best GPG values are attained by Vietnam $(0.82)$ and Thailand (0.78). The median GPG in this group is 0.58 . The lowest ranking are observed in predominantly Muslim countries, with GPG values of 0.17 for Algeria and Iran, and 0.18 for Jordan and Pakistan.

Surprisingly, the situation is substantially better in the low income group. The worst GPG values in this group ( 0.4 for Uganda and 0.41 for Mali) are far better than their equivalents in the lower-middle income group. All other countries in this group have a GPG above 0.5 , with a median of 0.7 , and the best performing countries (Tanzania and Kenya) have GPGs much higher values $r$ than many upper-middle and even advanced economies ( 0.93 and 0.92 , respectively).

The data gathered in the WEF report permits several observations. First, both women's access to education (the GGE index) as well as pay equity (the GPG index) are only 
partially correlated with the overall condition of each country's economy (as reflected in per-capita GDP). Many countries in the lower-middle income group attain low gender-related indices values despite being more affluent than the low-income countries. This suggests that other, non-economic factors play a crucial role here. In particular, the conspicuous underperformance of Muslim countries indicates that culture background impacts the values of the indices. Countries in the low-income group (primarily African ones) provide better opportunities for women in terms of education and wages, despite a lower level of development.

Second, gender-related wage inequality is still commonly practiced, and is significant, in practically all countries regardless of how affluent or poor. Wealthy countries, such as Germany (GPG 0.84), France (0.75), the United States (0.65), and both Spain and Japan (0.60) all legally mandate gender equality.

Third, a gender equity in education (GGE) is less problematic then pay inequality. Excepting countries with a strong Islamic background, all countries considered in the report have GGEs of 0.78 or more, i.e., women account for (roughly) at least eighty percent of the literate population and students. This relatively strong educational attainment among women should enhance their future ability to participate in leadership roles in all types of organizations.

\section{The Proposed Taxonomy of Gender Inequality Determinants}

Underrepresentation of female leaders in organizational structures is just one of the manifestations of the broader phenomenon of gender inequality. This section focuses on classification of the causes of the latter.

Determinants (alternatively referred to as factors) responsible for gender inequality can be broadly divided into two categories: exogenous and endogenous. The former are contextual, socio-economic, and imposed by history, political situations, culture and beliefs within a society. Endogenous factors are strongly correlated with exogenous ones and can be triggered by them, but are mostly concerned with women's psychology: personal narratives formulating sets of self-beliefs, self-esteem, personality traits, and numerous identities.

Exogenous determinants of gender inequality include:

- historic background,

- legal and political state,

- women's economic situation (access to paid jobs, unpaid work),

- culture, and in particular:

- traditions [Miller, Hoffmann, 1995; Weber, 1946; Giddens et al., 2000],

- religion [Weber, 1946; Marx, McLellan, 2000; Wiesner 2000; Ozorak, 1996; Dollar, Gattin, 1999], 
- education [Bolzendahl, Myers, 2004],

- social acceptance [Giddens et al., 2000].

Endogenous determinants focus more on internal, predominantly psychological aspects, which in the context of this paper are understood as such that can thwart women's economic activity or career progress. Among them, the most impactful are personal characteristics in the exact and broader sense, e.g., intellectual capabilities, emotional intelligence, temperament, competitiveness likability, power of persuasion, and set of personal beliefs. In the context of leadership, personal characteristics have been studied with respect to:

- emotional intelligence and the sense of meaning [Goleman et al., 1994; Senge, 1994; Giddens, 1991],

- degree of willingness to comply with social roles [Mead, 1934; Biddle,1986; Smith, 2007],

- compliance with role congruity [Eagly, Karau, 2002],

- natural propensity for leadership traits [Drucker, 1995, Drucker, 2011; Senge, 1994, Giddens et al., 2000; Ely, 1994; Ely, 1995; Ely, Thomas, 2001; Ely and Meyerson 2000; Ibarra 1990; Ibarra et al., 2014; Eagly, Johnson, 1990],

- compatibility of adopted identities with expectations:

- self identity [Tajfel, 1974; Tajfel, Turner, 1979],

- social identity [Sherif, 1961; Senge, 1994; Senge, 2002; Giddens et al., 2000],

- leadership identity [Drucker, 2011; Ely, 1994; Komives et al., 2005].

The division of determinants is by no means a clear-cut. There is significant overlap and interdependence between particular factors within the exogenous and endogenous groups. Also, exogenous factors influence endogenous ones. Both exo- and endogenous factors have been instrumental in women's exclusion or inclusion in organizational structures.

The impact of these determinants on women's participation in labor markets can vary. Regardless of culture, exogenous factors seem to have a greater impact than endogenous ones on woman's chances of becoming a leader. Exogenous factors emerge from group behavior, and group's power of influencing the individuals. Group behavior is closely related to culture, the group's historic legacy and contemporary trends. Therefore, among exogenous factors, culture-related ones dominate and are universal within all economies. They are responsible for the most potent barriers of prejudice and discrimination, which depend on traditional canon of norms [Wiesner, 2000]. Culture-rooted determinants, especially those of an exogenous nature, such as bringing up girls in traditional, religion-influenced environments, creates misconceptions and imposes false self-beliefs, e.g., about broadly understood male supremacy. Such convictions can cause long-term psychological barriers, contribute to women's low self-esteem, and a lack of sufficient determination to pursue their careers [Dollar, Gatti, 1999]. Morgan's claim, quoted earlier, that some women with higher education degrees choose lower-paid job sectors, may reflect the importance of exogenous, culture-based determinants influencing endogenous ones [Morgan, 2015]. 
Organizations are steeped in, shaped by, and dependent upon cultural norms represented by an organization's members. We are all the products of our cultures, and cultures are the products of accumulated beliefs, traditions, established norms, and also newly arising trends (like those resulting from technological transformations). Cultural backgrounds enrich, but also challenge individuals and organizations. Here, we focus on the negative implications for socio-economic states that in the long run influence the overall state of organizations. Among the most obstinate culture constituents that require special attention are traditions, which can be interpreted as a culture's constituents that are often contradictory to progress. Traditions frequently trigger resistance to evolving views such as those pertaining to women's more favorable statutory place within organizations. Only after organizations take steps towards transcending their visions beyond traditional views they can allow for changes that impact managerial structures [Ely, Meyerson, 2000].

The dominating character of culture-related determinants is crucial because it directly translates into the state of women's leadership, and because of the interdependencies between culture and the economy [Giddens et al., 2000; Weber, 1946; Wiesner, 2000; Sapienza, Zingales, 2006; Ely, 1995; Eagly, 1997; Ibarra, 1995; Smith, Bettio, 2008]. One of the interesting works in which the culture/economy relation was analyzed is "Culture and Economy" [DiMaggio, 1994]. DiMaggio described culture in terms of its constitutive and regulative features, which are reflected in the economy. Cultures are constructed and controlled through adopted rules, which are based on certain ethical and economic values. They are also intrinsically linked to traditions and religion, making culture-rooted determinants very complex. A good example of a strong relationship between culture, and the economy and their impact on women are many Muslim countries, where the law depends on the interpretation of Koran, making it difficult to argue with.

DiMaggio concept of culture in the economic context operates like Adam Smith's ingenious idea of the "invisible hand", first described in 1759 in The Theory of Moral Sentiments, and further explained in the 1776 publication of The Wealth of Nations [Smith, ed. R.P. Hanley, 2010]. Also for DiMaggio, culture ultimately becomes a means for individuals to seek and fulfill their own self-interest [DiMaggio, 1994; Grampp, 2000]. One can question the timing necessary for a culture to transform the socio-political environment enough to allow the underprivileged to enjoy the potential benefits of such a remodeling, including the fulfillment of self-interests. A similar approach to culture influencing economic behaviors was proposed by [Sapienza et al., 2006], who argued that culture and economics are interrelated, and that the reluctance to associate these two has been caused by, among others, culture's broad scope and the vagueness with which it is defined. Sapienza et al. [2006] suggested that culture should therefore be understood as:

"customary beliefs and values that ethnic, religious, and social groups transmit fairly unchanged from generation to generation" [Sapienza et al., 2006].

In this sense the concept of women as a leader is still weak within certain culture settings and varied economic conditions and requires time to "naturally" establish itself. We can 
hope that this time period required to give women-leaders equal chances in organizations as these of men, will be shorter than time required to implement women's rights. Consistent with DiMaggio and Smith, we see an evolutionary context of developing organizations that until the $20^{\text {th }}$ century women, rendered women unable as a lobby group to surmount culture-based obstacles. Lack of male support and fear of violating established rules left women, as a social group, dispersed and fragmented. Men, strongly protective of their supreme social position took advantage of women's vulnerable statutory position, and abused their rights in various ways. For centuries, legally unprotected women added up to male material possessions, with no rights or chances to implement their ambitions. The impact of established traditions and beliefs has been reflected in the rife discriminatory policies and socio-economic abuse of women. Male social supremacy, and men's place in organizations dictated gender-based statutory place for women, or rather a lack of such a place. Reinforced by stereotypes systemic gender bias against women still presents itself as equality gap in pay, employment, access to education and particular jobs, and in the overall women participation in economy.

\section{Manifestations of Determinants of Gender Inequality}

Manifestations of gender inequality identified in the literature, which originate in the determinants summarized in the previous section, include:

- bias and prejudice,

- stereotyping,

- discrimination and exclusion,

- unequal pay,

- apparent perks,

- unequal practice opportunities,

- unpaid work.

Some of these manifestations pertain to mental attitudes, physical actions, or both. Those interactions involve group members within organizations and other social entities.

We argue that all these manifestations originate in culture, the major exogenous determinant, and more specifically in - the general perception of women's social roles [Ely et al., 2011; Ely, 1994, Ely, 1995; Eagly, 1997; Ibarra, 1995]. Therefore, we present the latter in a separate subsection where we briefly discuss the most common manifestations from the above list. Then, in the next subsection we focus on unpaid work which is often neglected in economic models. The last subsection provides a discussion. 


\section{General Perception of Women's Social Roles}

In every culture and economy historical background and social habits determine perceptions concerning women's roles in society. These perceptions contribute to pre-conditioning women (young women in particular) to their expected roles in society, and in organizations they enter.

Women are still perceived as less fit to study math or management, and more inclined to engage in 'gentler' subjects considered to better 'fit' women, like teaching, office administrative jobs, and nursing [L'Oreal Foundation, 2015; Donald, 2015], although the latter arguably does not fit into the 'gentle' jobs category. Also, women in reproductive age (which overlaps with the best years to begin a career), and mothers are at the highest risk of being discriminated against because absenteeism due to child care is among the greatest employers' fears when hiring women. Rather than creating a better work environment for women, employers are more concerned with potential losses. Instead of developing strong teams, or investing in individuals, some adopt short term approach, while in the long-term vision, it can be highly beneficial to invest in satisfied and loyal employees, as it has been proven by several pioneering companies like the SAS Institute, Microsoft, Coca-Cola, and Starbucks. In developed economies, where the tolerance for diversity is higher than in the poor countries, most misconceptions about women's participation in the economy are created at home or in school, and reinforced by sub-cultures [Giddens et al., 2000; Garcia-Retamero et al., 2006; Byerly, Ross, 2008]. In the contemporary world, social role stereotyping is, in many different ways, also strengthened by the media. Despite encouraging reports that favor female leadership effectiveness, in many places ambitious women are still being 'punished' for their aspirations, as described by Sandberg [2013], Eagly and Carli [2007], Hymowitz and Schelllhardt [1986], Ely et al. [2011], Brzezinski [2011], Myers [2002], and others.

Rigid stereotypes that permeate societies and organizations have prevented women from reaching high managerial posts. Some of these are born out of widespread prejudice based on negative connotations commonly associated with ambitious women [Ely, 1994; Ely, 1995; Eagly and Carli 2003; Myers, 2002]. Women aspiring to high posts can be unfairly characterized as ruthless, male-like, and unlikable, traits which can undermine their perception as competent experts. In some cultures or circles, such women would also still be considered as being 'incompatible' with the traditional image of a wife and a mother. This view has deep historical roots and still impacts many cultures. Contradictory attitudes not only in developing economies, but also for example, in the USA, contribute to negative perceptions of professionally ambitious women.

As studies show, competitive, ambitious women score low on likability scale. They are perceived as too bossy, dictatorial, power-thirsty, or, at the other end of the spectrum, indecisive, too gentle, or too emotional, a combination of characteristics indicating lack of leadership qualities [Eagly, Carli, 2003; Eagly, Carli, 2007; Blum et al., 1994; Britton, 2000]. 
Another obstacle for women leaders stems from the perception that they are more communal than men, who are usually considered more agentic, i.e., more task- than people-oriented and more competitive than cooperative [Eagly, Carli, 2003, 2007; Ely et al., 2011]. Women who are perceived as communal and empathetic, instead of being appreciated for those traits, may instead encounter mistrust and hostility. Because these 'positive' characteristics are not always accepted as such, women may feel compelled to adapt masculinized traits to survive as leaders, to appear more male like, or as tougher [Britton, 2000; Eagly, Carli, 2007; Ely, Padavic, 2007]. For example, it has been argued that Margaret Thatcher, or more recently Kim Campbell, the former Prime Minister of Canada in order to gain higher authority and higher degree of power as leaders, both compromised their feminine characteristics and adopted associated with masculinity traits. By working on their pitch, so that their voice would sound lower, more masculine, more compliant with the general perception of a leader women hope to gain more trust as leaders [Auer, 1979]. In 1979 Margaret Thatcher famously went through voice training sessions with Shakespearian actor Laurence Olivier, which indeed impacted her oral performances as a political leader. As pointed out by Eagly and Carli [2003], the tension between being communal or more agented is often crucial for performance of organizations, because it directly relates to the question of whether leaders should be more liked or more respected.

Although being communal or empathetic can in the broader perspective be perceived as negative, those traits can also be viewed as a leader's potential assets. Some of such 'friendly' traits, previously associated mostly with women, are recognized as beneficial in conflict-solving situations, and can open up new possibilities, helping women advance in an organization's hierarchy. High empathy in many mature organizations is already perceived as an indispensable trait of leaders, especially in the open system approach to organizations, as advocated by Senge [1999] and Giddens [1991].

\section{Manifestations of Gender Inequality in Organizations}

The word prejudice comes from Latin preajudicium, where 'prea' is translated as 'in advance' and 'judicium' as 'judgement' [Oxford, 2015]. The same source defines prejudice as "dislike, hostility, or unjust behavior deriving from preconceived and unfounded opinions". Bias, close in meaning to prejudice, is defined by the same source as "an inclination or prejudice for or against one person or group, especially in a way considered to be unfair" [Oxford, 2015]. In this study, we consider bias as less severe than prejudice, as the latter implies pre-judgement based on false preconceptions that originate in culture, and is often deliberate. Bias can be unintentional and more subtle than prejudice.

Stereotype refers to a historic background of a group, within which greatly simplified beliefs are created and passed-down to the next generation. Stereotype can be defined as "a widely held but fixed and oversimplified image or idea of a particular type of person or thing" [Oxford, 2015]. Widely adopted stereotypes of women's social roles are present 
across all market economies and have for generations contributed to the social exclusion of females.

Gender discrimination can be defined as: "Essentially, a set of widely shared conscious and unconscious mental associations [...]. Study after study has affirmed that people associate women and men with different traits and link men with more of the traits that connote leadership" [Eagly and Carli, 2007].

We can try to understand some mechanics behind discriminatory constructs and/or actions by applying theories such as categorization theory, minimal group paradigm and social identity theory [Tajfel, 1974; Tajfel, Turner, 1979]. These theories provide invaluable insights into the studies of in-group conflicts, which can include discrimination and bias. Tajfel's concepts of social identity and in-group behavior was tested by Sherif's studies [1961], further revealing the implications of social-identity theories for understanding group behaviors, which can be extrapolated and applied to the analysis of women's discrimination as leaders.

Very often at the root of all types of "exclusion" or discrimination (including those pertaining to, female leaders) is the fear of unfamiliarity. It can also be blamed for a low tolerance of things foreign to one's own perception [Sherif, 1961]. In male-dominated environments, women's presence can be perceived as infringing on the accepted status quo, and an intrusion that seeks to 'subdue' or dominate the 'familiar.' The presence of women can therefore potentially trigger aggression against, and resistance to, women-leaders, and women aspiring to top managerial positions.

An example of overt discrimination is employers' preference for childless women and male employees, rather than for mothers or young women [Branch, 1994]. That preference affects not only women applying for jobs, but also those already employed. According to a report published by the Department for Business, Innovation and Skills of the UK Government [Adams et al., 2015], one-third of pregnant women feel unsupported by their organization, nearly $30 \%$ were refused flexible work conditions, around $8 \%$ said that their employer was unhappy about them taking maternity leave, and $15 \%$ reported being given unsuitable work. Moreover, $11 \%$ of women reported being pressured to begin their maternity leave earlier, $14 \%$ were encouraged to take time off against their will, and $20 \%$ reported being mistreated because of their pregnancy.

On the other hand some employers offer attractive maternity-leave perks to pregnant women. However, as pointed out by Eagly, Carli [2007], such benefits can be misleading and contribute to hidden forms of female discrimination by excluding them from working environment. They can slow down or prevent women's economic advancement [Eagly, Carli, 2007]. Taking longer breaks and being alienated from the work environment can have numerous negative consequences, such as narrowing work-related social networks, staying behind rather than updating work-related know-how, or reinforcing negative endogenous determinants. In this sense, these 'benefits' can perniciously work against women's careers, especially for prospective leaders who need work experience [Adams et al., 2015]. 
Another example of gender-related discrimination is the metaphorical 'glass ceiling' [Hymowitz, Schellhardt, 1986], which refers to invisible barriers that keep women (and other minorities) from advancing up on an organizations' hierarchy ladders. When introducing that term, Hymowitz and Schellhardt aptly expressed women's situation stating that: "Even those few women who rose steadily through the ranks eventually crashed into an invisible barrier. The executive suite seemed within their grasp, but they just couldn't break through the glass ceiling" [Hymowitz and Schellhardt, 1986].

Today some scholars disagree with the concept of 'glass ceiling', or consider it a simplification, pointing out that the problem is more one of the complexity, rather than the impenetrability, of barriers. Since some women are in the top hierarchies of organizational structures, one might argue that the 'impenetrability' aspect is no longer valid [Eagly, Carli, 2007]. But we cannot forget that in the light of statistics, when it comes to C-suits, we are often looking at outliers and the 'glass ceiling' has not completely disappeared. Barriers still prevent women's career advancement, which is perhaps best demonstrated by countries with the lowest ranks of the Global Gender Gap Index [Samans et al., 2015], such as Yemen, Pakistan, Chad, Syria or Islamic Republic of Iran.

Another study carried in the EU by L'Oreal Foundation [2015] revealed significant bias against women's scientists. According to this study, $89 \%$ of approximately 5,000 respondents stated that women are not good at science, $67 \%$ considered women not suited for scientific professions, $45 \%$ of women believed that men prevent women from advancing on a career ladder, and $44 \%$ pointed to a lack of support from higher management. The subject of women's performance in math was extensively discussed by Spencer et al. [1999].

Juxtaposition of these figures with an analogous study conducted in China [Donald, 2015] suggests the crucial role of culture-based determinations on bias and prejudice against women: $93 \%$ of Chinese respondents considered women unsuitable for scientific work. It is particularly striking that this preconception is shared by women themselves in that culture.

\section{Unpaid work}

An important, yet often overlooked, example of a strong negative determinant preventing women's advancement is unpaid work. The most common forms of unpaid work are typical household activities such as cleaning, cooking, child care and other forms of 'informal labor.' Other forms include providing free educational services and voluntary work in collegial bodies like school PTAs or churches. While some degree of unpaid work is unquestionably beneficial for givers and takers, problems arise when voluntary work is the only available source of social inclusion. In such cases, unpaid work often leads to exploitation [Goldschmidt-Clermont, 1982].

The socioeconomic impact of unpaid work becomes particularly important when combined with too low or too high fertility rates. Concerning the former, the aging population of the EU-28 is particularly concerned with the fertility problems. While providing effective 
social and economic mechanisms encouraging women to bear children is an important policy goal it should not be done, at the expense of women's career opportunities or make unpaid work the primary form of social inclusion and recognition. The implementation of some necessary changes (providing easy access, affordable child care facilities) still meets with barriers [Smith, Bettio, 2008].

High fertility rates combined with unpaid work contributes to women's insecurities and vulnerability. In densely populated developing countries like India and China, and in Africa, women's insecurities act as triggers, stimulating their dependence on men leading to suppression of self-development and economic independence. Women living in poverty are often uneducated and have limited rights to make decisions about their lives. The statutory social place dictates their roles and makes women an easy target for exploitation. Early and/or multiple pregnancies carry with them other serious problems for women's lives and careers. Unpaid work comes with motherhood, and can leave little time left for other activities, creating insurmountable, culture-rooted problems with serious socio-economic repercussions in a micro-, meso- and macro-scale.

Informal employment and unpaid work clearly originate in gender role stereotyping. Culture-rooted stereotypes impose restrictions on socially acceptable forms of the utilization of women's skills and reduce women's access to official labor markets. Indeed, despite often being better educated than men [Eccles, 1994; Fausto-Sterling, 2008], the utilization of women's skills still lags behind utilization of men's skills. Gender role rigidity, insufficient child care support, and the general consent for women's voluntary work create difficult to penetrate barriers, and slows down advancement.

Despite its presence in all cultures, unpaid labor is often neglected by macro- and micro-economic models [Lewis, 1993]. The household-related services provided by women remain in the economic grey zone, even though the economic impact of this phenomenon is substantial. We agree with Goldschmit-Clermont that there are three main economic repercussions of unpaid work that apply mostly to developed countries [Goldschmidt-Clermont, 1982]:

- low return on investment in female higher education,

- low tax return resulting from women's informal employment, such as performing household-related chores rather than outsourcing them,

- contribution to unemployment and claiming benefits.

There are few, already practiced, effective economic incentives for changing the status quo. Unfortunately, a current lack of understanding and myopic focus obstructs potential economic gains from alternatives to unpaid work. Some relatively easy changes to introduce include:

- improved education,

- better access to birth control,

- allowing women to make reproductive decisions without external pressure, i.e., become mothers willingly rather than face the consequences of uncontrolled pregnancies, 
- providing support for paid work,

- better utilization of women's skills,

- well-designed equality policies and fair access to career opportunities.

Effective implementation of well-designed equality laws would contribute to: lowering barriers raising awareness about detrimental consequences of excessive unpaid work, and to the more sustainable socio-economic progress [Rubery et al., 2004].

\section{Discussion}

Gender, like race, is a part of natural human diversity. Because of this diversity we face barriers, sometimes leading to serious discriminatory behaviors such as cases of public ostracism. These barriers play a meaningful role in the absence of women leaders in the C-Suits of organizations. Some of the negative factors discussed above are often subtle (e.g. sexual innuendoes implying women's subdued roles, implicit bias), and therefore difficult to investigate. Others are more obvious and therefore easier to address. The visible factors manifest themselves more in the "open-field" battles. One side of the conflict reaches for the above-mentioned 'weapons' of creating, sustaining glass-ceiling barriers, wage inequality, discrimination against pregnant women, women-mothers, and aging women, among others [Waldfogel, 1997; Sanberg, 2012; Brzezinski, 2010; O’Neill, Polachek, 1993]. On the other side are tools to defend women, and these are fairness and gender equality approaches to employment realized through, among others, organizational support, well designed and implemented programs and policies.

This interplay of the external and internal factors discussed above has shaped how women approach or exercise leadership today. Female leadership in the context of culture is related to "conscious and unconscious mental associations," which play a paramount role in establishing norms or prescribing individuals to their various social roles [Eagly, Carli, 2007]. Some of these "mental associations" concern and strengthen negative culture-based bias against women leaders. They have often contributed to polarization between women identities and societal expectations. The lack of environmental support, as well as an insufficient level of social understanding for women's aspirations, additionally undermines women's trust in merit-based organizational structures, moving women further away from achieving their career goals [Ely et al., 2011; Ely, Padavic, 2007].

It is often claimed that, stereotyping, prejudice and bias have played a central role among the culture-rooted manifestations hindering women's progress as leaders [Ely et al., 2011; Ibarra, 1993; Ibarra et al., 2014]. The main problem with such barriers is the potential impact on women's self-esteem, which may lead to internal polarization of women's personal identity and that of a leader. Such situations may be amplified by men succumbing to attribution errors, meant as misinterpretation of the causes of other people's behavior. Men, who for centuries dominated organizational structures, have historically attributed women's underrepresentation in top organizational hierarchy to women's inability to take important decisions, such as these related to managing organizations. Another reason for 
men blocking women's advancement may be a misunderstanding of the motives behind women's aspirations, assuming that women are power thirsty rather than competent and well-suited for top managerial positions [Lerner, Miller, 1978; Pettigrew, 1979; Eagly, Carli, 2007].

\section{Organization as Leaders' Natural Environment}

The word "organization", is derived from a verb "to organize", i.e., "to make arrangements for (something) to happen" [Cambridge, 1995]. The Business dictionary provides a broader definition and describes an organization as:

"a social unit of people that is structured and managed to meet a need or to pursue collective goals. All organizations have a management structure that determines relationship between the different activities and the members, and subdivides and assigns roles, responsibilities and authority to carry out different tasks. Organizations are open systems-they affect and are affected by their environment" [Business dictionary, 2015].

Both descriptions of "organizations" share the notion of "togetherness," meaning cooperation - and management plays an important role in learning organizations as described by Senge, i.e., organizations where people continually evolve and follow their aspirations [Senge, 1990]. Senge's approach provides a thorough, multidimensional insight into the organization as a complex system, which creates its own identity and seeks to treat all its members fairly and with respect. In such organizations, gender aspect has no relevance in evaluating leader's effectiveness, or creating opportunities. However, it matters in terms of providing adequate working and developmental conditions. In a practical application of Senge's theory, a learning organization would identify and act on a problem to meet the needs of its members. In the case of females, organizations should notice their needs, including those strictly gender-related, e.g. provide facilities as prosaic as separate toilettes, or parking lots for pregnant women. Practical organizational adaptations were well described by Sheryl Sandberg in her practice-based experience as a woman-leader, the CEO of Facebook [Sandberg, 2013].

Organizations and their leaders are interdependent, relying on mutual trust, influence, and contributions to each another [Ely 1994; Ely 1995; Acker 1990; Ibarra, 1993; Wood, Bandura, 1989; Giddens 1991; Senge, 1990; Hofstede et al., 1997]. An important and interesting consequence of organizations as multi-level hierarchies is that most leaders, except those at the very top, are also themselves subordinates: the leader of a given group has another leader as his/her superior. This dual role can be a challenge, because different traits and personal qualities are essential to perform well in these two contexts. Men with strong leadership traits determined to pursue their careers and ambitions may be charismatic but unable to perform well as subordinates of other leaders, i.e., their superiors. It 
might be argued that characteristics traditionally associated with females, in particular being conciliatory, communal, and exhibiting other cooperative traits, can readily meet the requirements posed by these two polarized roles.

There is also an important temporal aspect of organizations. Leaders are often responsible for maintaining existing structures (universities, companies, countries), many of which are a legacy of previous leaders intended to be passed on to the next generations. These leaders are thus responsible to maintain and improve the current state of affairs within an organization. Recently, much attention has been given to innovation and technological advancement, putting pressure on the future of organizations and often disregarding their past. This rather approach may disregard the past, including historical and cultural backgrounds. As argued in the previous section, embracing cultural backgrounds is essential to understanding the factors influencing women's place within organizations.

In addition to the dynamic nature of organizations and the importance of cultural background, arguably the most challenging aspect of organizations is their complexity. Organizations are classical exemplifications of complex systems, i.e., conglomerates of large numbers of interwoven entities that interact with each other; and the overall outcomes of those interactions are often more than a direct consequence of laws that govern those interactions [Mitchell, 2009]. In other words, organizations may exhibit emerging properties, i.e., properties that are not anticipated given the elementary laws of interactions between the constituents, and synergic properties, i.e., properties that are "greater than the sum" of the properties of the components. Such properties are hard to predict and control and many organizations have experienced examples of the unanticipated consequences of managerial decisions.

Apart from this type of complexity, organizations can be viewed as complex in at least one other sense, i.e. the internal complexity posed by the individuals that form an organization. People in organizations not only interact with each other, create internal cultures within organizations, but also lead their autonomous existence and operate on both levels: as individuals functioning within and outside their working environments. Individuals and groups can elicit rich internal dynamics and personalities, and are interdependent components of a system [Senge, 1994; Giddens, 1986; Corning, 1995]. Such complexity makes it even more difficult to control organizations and predict their future behavior.

\section{Gender Disparity in Top Managerial Positions in Organizations}

Since organizations can be compared to a living organism Senge [1994], and can be considered an open systems capable of thinking, they are also susceptible to adopting prevailing social perceptions, including biases, prejudices, and stereotypes. Therefore, they need to be aware of such susceptibilities and act fast when change or intervention are 
needed. Unfortunately, the characteristics reviewed in the previous section (complexity, strong cultural roots, and temporal inertia) can slow down organizations' adaptability to changes. According to a recent report published by the Catalyst Research Center for Equity in Business Leadership [Catalyst, 2014], as of October 2014, in only a handful of countries women's share of board seats exceeds $25 \%$; these are: Norway (35.5\%), Finland (29.9\%), France (29.7\%), and Sweden (28.8\%). Overall, Europe seems to be most advanced in this area, and there are four more countries in that ranking (Belgium, UK, Denmark and the Netherlands) for which this indicator is higher than for the North American economies, i.e., $19.2 \%$ for the US and $20.8 \%$ for Canada. In Asia and the Pacific region, only Australia maintains comparable standards (19.2\%); the shares for India and Hong Kong are around $10 \%$, and Japan closes the world-wide ranking with $3.1 \%$.

It is worth noting that these numbers can be biased, because the report reflects only the organizations (in this case companies) included in selected stock indices (e.g., only 24 companies for Norway, the leader in the ranking, 60 companies for Canada, and 29 companies for Japan). As a result, this ranking characterizes only the largest enterprises, which presumably have strong international connections. Such companies are arguably exposed to more 'universally embraced values' and can be expected to have relatively high levels of awareness of gender equality. It is thus likely that the analogous numbers for smaller companies not included in the most prestigious stock indices are bleaker. See [Catalyst, 2014] for details.

Gender disparity clearly correlates with status in the management hierarchy. While only $4.6 \%$ of CEOs in large US enterprises are women (S\&P 500 companies, as of 2015 [Catalyst, 2015], the fraction of board seats occupied by women is $19.2 \%$. Further down the hierarchy, the share of women executive/senior-level official and managers is $25.1 \%$, and even higher (36.8\%) for the first/mid-level officials and managers. Compared to these numbers, almost half (45\%) of labor force in the S\&P 500 companies are female. This 'pyramid' indicates the existence of a 'glass ceiling' for women (literature hardly discusses glass ceiling for men).

Though these results fall short of gender parity, recent years have brought substantial and qualitative changes. The authors of Fortune's Most Powerful Women in Business ranking for 2014 observed a substantial shift of market sectors with respect to enterprises led by women CEOs [Fortune, 2015]. While the first such ranking published by Fortune in 1998 featured mostly women leading companies from "industries with a premium on creativity", i.e., advertising, media, and publishing, many women CEOs in the contemporary ranking represent blue-chip firms: the technology, defense, energy, and automotive industries.

When comparing various statistics we often rely on 'statistical significance. However, the absence of statistical significance does not necessarily need to imply lack of an impact. Eagly and Carli [2003] illustrated the importance of seemingly insignificant statistical variations, quoting the impact of medical studies on population. The researchers chose the example of aspirin uptake in relation to heart attacks, showing that relatively small 
statistical changes can have meaningful implications on people's life. Similarly, even small changes in relation to female leadership can trigger positive transformations, or, to the contrary, be the auguries of regress. In their studies Eagly and Carli also pointed out to earlier research on statistical insignificance having major repercussions [Abelson, 1985; Bushman and Anderson, 2001].

Misinterpretation of statistics can distort the actual perception of reality. As posited by Eagly and Carli [2007], another factor that can falsify the actual status of women's leadership is putting few female CEOs in the media spotlight. In statistical terms, these rare individuals constitute outliers, i.e., isolated observations (data points) located far away from the central tendency. In reality, female leadership is still uncommon in advanced economies and completely absent in many of the less affluent ones, especially in the developing countries.

It is important to point out that when analyzing women's place in organizations, we are not trying to suggest that women require special treatment to compensate for their more up-the-hill path leading to successful career. Like their male counterparts, women need to be given equal opportunities and be fairly evaluated on their leadership effectiveness, rather than be seen through the lenses of bias [Ely, 1995]. There is also a noticeable body of leadership studies that can be applied to leaders of both genders. However, the pool of shared characteristics does not imply that both genders are identical. Certain differences in genders and in their perceptions are scientifically proven and should not be ignored; these include, some biological and psychological differences, which are important, particularly when trying to better understand leadership.

\section{Conclusions}

In this paper, we brought much evidence that the current situation of women in higher strata of organizational structures leaves much to be desired. Nevertheless, some progress has been made, in particular in the recent decades, and chances are that it will be taken further. The ongoing and planned legal and economic measures seem to indeed be changing the current state of affair.

The 1995 Beijing Declaration and Platform for Action [UN, 1995], and policies proposed by the European Employment Strategy indicate that progress can be made but requires work. Hopefully, reaching full parity will take less time than the historical path required to implement gender equality rights. Spain's 2007 Equality Law, which encourages large companies to have at least $40 \%$ quota of women in their boards, is an example of new measures taken to broaden women's access to top managerial positions [Lombardo, 2008]. The Scandinavian model of state support is another effective example of this practice. We can therefore say that well-developed endorsement for women through governmental 
regulations positively transformed the socio-economic spheres in Scandinavia. This change was obtained by providing e.g., child care facilities, lowering the rates of unpaid employment, regulating birth rate statistics and reducing the overall gender gap, which enabled women to more fully contribute to the economy [Plantenga, Remery, 2008; Lewis 1993].

The prevailing reluctance to admit the existence of problems related to women's inequality may seem more of political rather than economical one. It can be a result of a short-term vision and misconceptions that come from misguided fears of high economic costs of equality reforms [Humphries, Rubery, 1995]. Some practices on the corporate level, implemented by companies such as Intel, Coca-Cola, Google and Facebook, provide additional arguments in favor of multiple benefits of women's inclusion in the labor market and leadership positions. Measures exercised by some HPOs or countries like Sweden are also reflected in new HR policies, which, among others, promote work-family balance, reduced unpaid work and satisfying, paid work. These companies also introduce flexible working hours and voluntary quotas for women holding senior positions.

Women are making essential contributions to economy and their presence in leadership has positive impact on organizations, which suggests that a more gender-balanced organizational structure transcends politics and ideologies and it is justified by economic indicators. The main conclusion of this study is that easier access for women to labor market and to C-Suits is a worthwhile investment with long-term positive socioeconomic consequences for all society members, regardless of gender or other characteristics. With a rapidly growing world's population, the economic repercussions of reducing gender disparity are likely to be of significance to all economic states. Currently, women constitute $49.6 \%$ of the world's population [The World Bank, 2015], which reflects the unquestionable potential of this still underrepresented group.

Women inclusion within societies and organizations is arguably on the rise. As scholars like Steven Pinker [2011] claim, the economic and safety-related conditions of life are better now than ever before. This trend can be extrapolated to women's place in organizational structures which, as we said, is gradually changing in women's favor. If Pinker's hypothesis is correct, if societies are becoming more humanitarian, more egalitarian, we may hope for an exponential progress towards gender parity in C-suits, and for the unbiased treatment of genders in organizational structures.

Given the pace of changes in the last decade and their impact on organizations, contemporary organizations need to be open to transformations, while leaders, more than ever, are in need of continuous updates of their knowledge. It will be interesting to see how will women-leaders measure up to these changes. With the support from policymakers and organizations, there is a realistic chance that gender gaps will be further reduced or eliminated, allowing women to work in healthy, merit-based organizations. 


\section{Acknowledgements}

I would like to thank Professor Małgorzata Bartosik-Purgat and the anonymous reviewers (one of them in particular) for their valuable remarks. I am also grateful to the RSA and Sir Tony Atkinson for his inspirational 2015 RSA President's lecture, which prompted some of the thoughts reflected in this article.

\section{Notes \\ 1 Author's e-mail address: al.krawiec@gmail.com}

\section{References}

Acker, J. (1990), Hierarchies, jobs, bodies: A theory of gendered organizations, Gender \& Society, Vol. 4, No. 2, pp. 139-158.

Adams, L., Winterbotham, M., Oldfield, K., Large, A., Stuart, A., Murphy, L., Rossiter, H., Selner, S. (2015), Pregnancy and Maternity Related Discrimination and Disadvantage First findings: Surveys of Employers and Mothers, Department for Business, Innovation and Skills, BIS Research Paper, No. 235, IFF Research.

Auer, J.J. (1979), The image of the right honorable Margaret Thatcher, Communication Studies, Vol. 30, No. 4, pp. 289-310.

Bandura, A., Wood, R. (1989), Effect of perceived controllability and performance standards on self-regulation of complex decision making, Journal of personality and social psychology, Vol. 56, No. 5, pp. 805-814.

Baker, M., Milligan, K. (2008), How Does Job-Protected Maternity Leave Affect Mothers' Employment?, Journal of Labor Economics, Vol. 26, No. 4, pp. 655-691.

Berger, L.M., Hill, J., Waldfogel, J. (2005), Maternity leave, early maternal employment and child health and development in the US, The Economic Journal, Vol. 115, No. 501, pp. F29-F47.

Biddle, B.J. (1986), Recent Developments in Role Theory, Annual Review of Sociology, Vol. 12, pp. 67-92.

Blum, T.C., Fields, D.L., Goodman, J.S. (1994), Organization-level determinants of women in management. Academy of Management Journal, Vol. 37, No. 2.

Bolzendahl, C.I., Myers, D.J. (2004), Feminist attitudes and support for gender equality: Opinion change in women and men, 1974-1998, Social Forces, Vol. 83, No. 2, pp. 759-789.

Bowcott, O. (2014), Twitter intimidation not taken seriously enough by police, says Stella Creasy, The Guardian, Sept. 29, 2014.

Branch, K. (1994), Are Women Worth as Much as Men: Employment Inequities, Gender Roles, and Public Policy, Duke Journal of Gender Law and Policy, Vol. 1, No. 119.

Britton, D.M. (2000), The epistemology of the gendered organization, Gender $\triangleleft$ Society, 4.3, pp. 418-434.

Brzezinski, M. (2011), Knowing Your Value: Women, Money and Getting What You're Worth, Weinstein Books. 
Businessdictionary (2015), http://businessdictionary.com

Byerly, C.M., Ross, K. (2008), Women and media: A critical introduction, John Wiley \& Sons.

Cambridge International Dictionary of English (1995), Cambridge University Press, Cambridge, UK.

Carter, N.M., Wagner, H.M. (2011), The Bottom Line: Corporate Performance and Women's Representation on Boards (2004-2008), Catalyst Report, March 2011, available at:http://www.catalyst.org/knowledge/bottom-line-corporate-performance-and-womens-representation-boards-20042008, accessed: retrieved in August, 2015.

Catalyst (2014),Catalyst Census: Women Board Directors, New York: Catalyst.

Catalyst (2015),Pyramid: Women in S\&P 500 Companies, New York: Catalyst, April 3, 2015.

Chickering, A.W. (1969), Education and identity, Jossey-Bass, San Francisco, CA.

Corning, P.A. (1995), Synergy and self-organization in the evolution of complex systems, Systems Research, Vol. 12, No. 2, pp. 89-122.

Datta Gupta, N., Smith, N., Verner, M. (2008), The impact of Nordic countries' family friendly policies on employment, wages, and children, Rev Econ Household, Vol. 6, pp. 65-89.

Donald, D.A. (2015), 67\% of Europeans don't believe women have the skills to be scientists, Women in Leadership, The Guardian, September 24, 2015.

DiMaggio, P. (1994), Culture and Economy, in: Neil Smelser and Richard Swedberg (eds.), The Handbook of Economic Sociology, Princeton University Press, Princeton, NJ, pp. 27-57.

Dollar, D., Gatti R., (1999), Gender inequality, income, and growth: are good times good for women?. Vol. 1. Washington, DC: Development Research Group, The World Bank.

Drucker, P.F. (1995), People and performance: The best of Peter Drucker on management, Routledge.

Drucker, P.F. (2011), The age of discontinuity: Guidelines to our changing society, Transaction Publishers.

Eagly, A.H., Kite, M.E. (1987), Are stereotypes of nationalities applied to both women and men?, Journal of Personality and Social Psychology, Vol. 53, No. 3, pp. 451.

Eagly, A.H. (1987), Reporting sex differences, American Psychologist, Vol. 42, No. 7, pp. 756-757.

Eagly, A.H., Karau, S.J. (1991), Gender and the emergence of leaders: A meta-analysis, Journal of Personality and Social Psychology, Vol. 60, No. 5, pp. 685-710.

Eagly, A.H. (1997), Sex differences in social behavior: comparing social role theory and evolutionary psychology, American Psychologist, Vol. 52, No. 12, pp. 1380-1383.

Eagly, A.H., Johannesen-Schmidt, M.C. (2001), The leadership styles of women and men, Journal of Social Issues, Vol. 57, No. 4, pp. 781-797.

Eagly, A.H., Johannesen-Schmidt, M.C., Van Engen, M.L. (2003), Transformational, transactional, and laissez-faire leadership styles: a meta-analysis comparing women and men, Psychological Bulletin, Vol. 129, No. 4, pp. 569-591.

Eagly, A.H., Carli, L.L. (2003), The female leadership advantage: An evaluation of the evidence, The Leadership Quarterly, Vol. 14, No. 6, pp. 807-834.

Eagly, A.H. (2004), Few women at the top: How role incongruity produces prejudice and the glass ceiling, in: D. van Knippenberg,, M.A. Hogg. (eds.), Leadership and power: Identity processes in groups and organizations, Sage Publications, London, pp. 79-93.

Eagly, A.H., Carli, L.L. (2007), Women and the labyrinth of leadership, Harvard Business Review, Vol. 85, No. 9, pp. 62-82.

Eagly, A.H. (2009), The his and hers of prosocial behavior: an examination of the social psychology of gender, American Psychologist, Vol. 64, No. 8, pp. 644-658.

Eccles, J.S. (1994), Understanding women's educational and occupational choices, Psychology of Women Quarterly, Vol. 18, No. 4, pp. 585-609. 
Ely, R.J. (1994), The effects of organizational demographics and social identity on relationships among professional women, Administrative Science Quarterly, Vol. 39, No. 2, pp. 203-238.

Ely, R.J. (1995), The power in demography: Women's social constructions of gender identity at work", Academy of Management Journal, Vol. 38, No. 3, pp. 589-634.

Ely, R.J., Meyerson, D.E. (2000), Advancing gender equity in organizations: The challenge and importance of maintaining a gender narrative, Organization, Vol. 7, No. 4, pp. 589-608.

Ely, R.J., Ibarra, H., Kolb, D.M. (2011), Taking gender into account: Theory and design for women's leadership development programs, Academy of Management Learning \& Education, Vol. 10, No. 3, pp. 474-493.

Ely, R.J., Thomas, D.A. (2001), Cultural diversity at work: The effects of diversity perspectives on work group processes and outcomes, Administrative Science Quarterly, Vol. 46, No. 2, pp. 229-273.

Ely, R., Padavic, I. (2007), A feminist analysis of organizational research on sex differences, Academy of Management Review, Vol. 32, No. 4, pp. 1121-1143.

Ely, R., Ibarra, H., Kolb, D. (2011), Taking Gender Into Account. Theory and Design for Women's Leadership Development Programs, Academy of Management Learning and Education, Vol. 10, No. 3, pp. 474-493.

Eurostat (2014), Statistics Explained, available at: http://ec.europa.eu/eurostat/statistics-explained/index.php Fausto-Sterling, A. (2008), Myths of gender: Biological theories about women and men, Basic Books.

Fortune (2014), The Most Powerful Women in Business, available at: http://fortune.com/most-powerful-women/, accessed: August 2015.

Giddens, A. (1971), Capitalism and modern social theory: An analysis of the writings of Marx, Durkheim and Max Weber, Cambridge University Press, Cambridge, UK.

Garcia-Retamero, R., López-Zafra, E. (2006), Prejudice against women in male-congenial environments: Perceptions of gender role congruity in leadership, Sex roles, Vol. 55, No. 1-2, pp. 51-61.

Giddens, A. (1984), The constitution of society: Outline of the theory of structuration. University of California Press. Giddens, A. (1991),Modernity and self-identity: Self and society in the late modern age, Stanford University Press. Giddens, A., Duneier, M., Appelbaum, R.P., et al. (2000), Introduction to sociology, New York, WW Norton. Giddens, A. (2002). Runaway world: How globalization is reshaping our lives, Profile Books.

Giddens, A. (2004), Beneath the hijab: A woman, New Perspectives Quarterly, Vol. 21, No. 2, pp. 9-11.

Giddens, A. (2013), The consequences of modernity, John Wiley \& Sons.

Goldschmidt-Clermont, L. (1982), Unpaid work in the household: a review of economic evaluation methods, International Labour Office, Geneva, Switzerland.

Grampp, W.D. (2000), What did Smith mean by the invisible hand?, Journal of Political Economy, Vol. 108, No. 3, pp. 441-465.

Gratton, L., Erickson, T.J. (2007), Eight ways to build collaborative teams, Harvard Business Review, Vol. 85, No. 11, pp. 100-109.

Humbert, A.L., Ivaškaitė-Tamošiūnè, V., Oetke, N., Paats, M. (2015), Gender Equality Index 2015 - Measuring gender equality in the European Union 2005-2012, European Institute for Gender Equality.

Humphries, J. (1995) Economics, Gender and Equal Opportunities, in: J. Humphries, J. Rubery (eds.), Economics of Equality, Equality Commission, Manchester, UK.

Hofstede, G., Hofstede, G.J., Minkov, M. (1997), Cultures and organizations, McGraw Hill, New York, NY.

Hymowitz, C., Schellhardt, T.D. (1986), The Glass Ceiling: Why Women Can't Seem to Break The Invisible Barrier That Blocks Them From the Top Jobs, Wall Street Journal, March 1986.

Ibarra, H. (1993), Personal networks of women and minorities in management: A conceptual framework, Academy of Management Review, Vol. 18, No. 1, pp. 56-87. 
Ibarra, H. (1995), Race, opportunity, and diversity of social circles in managerial networks, Academy of Management Journal, Vol. 38, No. 3, pp. 673-703.

Ibarra, H. (2005), Identity transitions: possible selves, liminality and the dynamics of career change, INSEAD Working Paper.

Ibarra, H., Wittman, S., Petriglieri, G., Day, D.V. (2014), Leadership and Identity: An Examination of Three Theories and New Research Directions, in: D.V. Day (ed.), The Oxford handbook of leadership and organizations, Oxford Library of Psychology, Oxford University Press, USA, pp. 285-300.

ILO International Labour Organization (2014), Global Employment Trends 2014: Risk of a jobless recovery? accessed: in January 2015.

Kelly, E., Dobbin, F. (1999), Civil rights law at work: Sex discrimination and the rise of maternity leave policies, American Journal of Sociology, Vol. 105, No. 2, pp. 455-92.

Kim, D.H., Senge, P.M. (1994), Putting systems thinking into practice, System Dynamics Review, Vol. 10, No. 2-3, pp. 277-290.

Komives, S.R., et al. (2005), Developing a leadership identity: A grounded theory, Journal of College Student Development, Vol. 46, No. 6, pp. 593-611.

Lerner, M.J., Miller, D.T. (1978), Just world research and the attribution process: Looking back and ahead, Psychological Bulletin, Vol. 85, No. 5, pp. 1030.

Lewis, J.E. (1993), Women and social policies in Europe: work, family and the state, Edward Elgar Pub.

L'Oreal Foundation (2015), Women in Science Report 2015, available at: http://www.loreal.com/media/press-releases/2015/sep/the-loreal-foundation-unveils-the-results-of-its-exclusive-international-study

Lyness, K.S., et al. (1999), Work and pregnancy: Individual and organizational factors influencing organizational commitment, timing of maternity leave, and return to work, Sex Roles, Vol. 41, No. 7-8, pp. 485-508.

Marx, K., McLellan, D. (2000), Karl Marx: Selected Writings, Oxford University Press.

Mead, G.H. (1934), Mind, Self, and Society, University of Chicago Press, Chicago, IL.

McKinsey and Company (2007), Women Matter: Gender Diversity, a corporate performance driver, McKinsey and Company - France, available at: http://www.mckinsey.com/features/women_matter

Miller, A.S., Hoffmann, J.P. (1995), Risk and religion: An explanation of gender differences in religiosity, Journal for the Scientific Study of Religion, Vol. 34, No. 1, pp. 63-75.

Morgan, N. (2015), Speech at UN Women UK and Government Equalities Office Conference, 27 February 2015 (speech transcript), available at: https://www.gov.uk/government/speeches/un-women-uk-and-government-equalities-office-conference

Myers, L.W. (2002), A broken silence: Voices of African American women in the academy, Greenwood Publishing Group.

Mitchell, M. (2009), Complexity: A Guided Tour, Oxford University Press: New York, NY.

OECD (2012), Gender Equality in Education, Employment and Entrepreneurship: Final Report to the MCM 2012, Organization for Economic Cooperation and Development (OECD), available at: http://www.oecd. org/employment/50423364.pdf

O'Neill, J., Polachek, S. (1993), Why the gender gap in wages narrowed in the 1980 s, Journal of Labor Economics, Vol. 11, No. 1, pp. 205-228.

Oxford (2015) Oxford University Press, Online Dictionary.

Ozorak, E.W. (1996), The power, but not the glory: How women empower themselves through religion, Journal for the Scientific Study of Religion, Vol. 35, pp. 17-29.

Pettigrew, T.F. (1979), The ultimate attribution error: Extending Allport's cognitive analysis of prejudice, Personality and Social Psychology Bulletin, Vol. 5, No. 4, pp. 461-476. 
Pinker, S. (2011), The Better Angels of Our Nature: Why Violence Has Declined, Viking, New York, NY.

Plantenga, J., Remery, R. (2008), The provision of childcare services: a comparative review of thirty European countries, Co-ordinators' synthesis report prepared for the Equality Unit, European Commission.

Rubery, J., Figueiredo, H., Smith, M., Grimshaw, D., Fagan, C. (2004), The ups and downs of European gender equality policy, Industrial Relations Journal, Vol. 35, No. 6, pp. 603-628.

Samans, R., Blanke, J., Corrigan, G., Drzeniek, M. (2015), The Inclusive Growth and Development Report, World Economic Forum, available at: http://reports.weforum.org/inclusive-growth-report-2015

Sandberg, S. (2013), Lean in: Women, work, and the will to lead, Random House.

Sapienza, P., Zingales, L., Guiso, L. (2006), Does culture affect economic outcomes?, Journal of Economic Perspectives, Vol. 20, No. 2, pp. 23-48.

Schwab, S. (1986), Is Statistical Discrimination Efficient?, The American Economic Review, Vol. 76, No. 1, pp. 228-234.

Schwartz, F.N. (1989), Management women and the new facts of life, Harvard Business Review, Vol. 89, pp. 65-76. Senge, P.M. (1990), The Fifth Discipline: The Art and Practice of The Learning Organization, Doubleday/Currency. Senge, P.M. (1994), Learning to Alter Mental Models: Learning accelerates as managers change their mental models. Executive Excellence, Vol. 11, pp. 16-17.

Senge, P.M. (1999), Leadership in living organizations, in: F. Hesselbein, et al., (eds.), Leading Beyond the Walls. Jossey-Bass, New York.

Senge, P.M. (2002), The Leader's New Work: Building Learning Organizations, Sloan Management Review, Vol. 32, No. 1, pp. 7-23.

Senge, P.M. (2014), The fifth discipline fieldbook: Strategies and tools for building a learning organization, Currency/Doubleday, New York.

Sherif, M., Hovland, C.I. (1961), Social judgment: Assimilation and contrast effects in communication and attitude change, Greenwood, Westport.

Sherif, C.W. (1982), Needed concepts in the study of gender identity, Psychology of Women Quarterly, Vol. 6, No. 4, pp. 375-398.

Smith, A. (2010), The theory of moral sentiments, Penguin, New York.

Smith, E. (2007), Social Psychology, Third Edition, Psychology Press, New York.

Smith, M., Bettio, F. (2008), Analysis note: the economic case for gender equality, European Commission's Network of Experts on Employment and Gender Equality issues (EGGE) report, European Union, available at: http:// eurogender.eige.europa.eu/sites/default/files/ECO-CASE-final-1.pdf

Spencer, S.J., Steele, C.M., Quinn, D.M. (1999), Stereotype threat and women's math performance, Journal of Experimental Social Psychology, Vol. 35, No. 1, pp. 4-28.

Tajfel, H. (1974), Social identity and intergroup behaviour, Social Science Information, Vol. 13, No. 2, pp. 65-93. Tajfel, H., Turner, J.C. (1979), An Integrative Theory of Intergroup Conflict, in: W.G. Austin, S. Worchel (eds.), The Social Psychology of Intergroup Relations, Brooks-Cole, Monterey, CA.

Tajfel, H. (1982), Social psychology of intergroup relations, Annual Review of Psychology, Vol. 33, No. 1, pp. 1-39. Tajfel, H. (2010), Social identity and intergroup relations, Cambridge University Press, Cambridge, UK.

The World Bank (2012), World Development Report: Gender Equality and Development, 2012, available at: http:// siteresources.worldbank.org/INTWDR2012/Resources/7778105-1299699968583/7786210-1315936222006/ Complete-Report.pdf

The World Bank (2015), World Development Indicators, available at: http://data.worldbank.org/indicator/SP.POP. TOTL.FE.ZS, accessed: September 2015. 
UN (1995), Beijing Declaration and Platform for Action, The Fourth World Conference on Women, Beijing, China, September 1995, available at: http://www.un.org/womenwatch/daw/beijing/pdf/BDPfA\%20E.pdf

UNW (2015), Progress of the World's Women 2015-2016: Transforming economies, realizing rights, United Nations Entity for Gender Equality and the Empowerment of Women, available at: http://progress.unwomen. org/en/2015/pdf/UNW_progressreport.pdf

World Bank Gender Data Portal (2015), available at: http://datatopics.worldbank.org/gender/key\%20gender\%20 employment\%20indicators, accessed: September, 2015.

United States Census Bureau (2015), World Population, accessed: September 2015, available at: http://www. census.gov/population/international/data/worldpop/table_population.php

Waldfogel, J. (1997), The effect of children on women's wages, American Sociological Review, Vol. 62, No. 2, pp. 209-217.

Worldometers (2015), available at: http://www.worldometers.info/world-population/

Weber, M., Gerth, H.H., Mills, C.W. (1946), From Max Weber: Essays in sociology, Oxford University Press, New York.

Wiesner, Merry E. (2000), Women and gender in early modern Europe, Cambridge University Press, Cambridge, UK. 